\section{SAT0028 THE FLARE-RA QUESTIONNAIRE CAN PREDICT FLARES IN PATIENTS WITH ESTABLISHED RHEUMATOID ARTHRITIS PARTICIPATING IN THE TAPERA TRIAL}

D. Bertrand ${ }^{1}$, D. De Cock ${ }^{1}$, V. Stouten ${ }^{1}$, S. Pazmino ${ }^{1}$, A. Moeyersoons ${ }^{2}$, J. Joly ${ }^{2}$, R. Westhovens ${ }^{1,2}$, P. Verschueren ${ }^{1,2} .{ }^{1} \mathrm{KU}$ Leuven, Skeletal Biology and Engineering Research Center, Leuven, Belgium; ${ }^{2}$ UZ Leuven, Rheumatology, Leuven, Belgium

Background: The Flare assessment in Rheumatoid Arthritis (FLARE-RA) questionnaire was developed to identify Rheumatoid Arthritis (RA) flares, but it is unknown if this questionnaire can also predict flares.

Objectives: To identify if the FLARE-RA questionnaire has a predictive capacity for OMERACT flares in patients with established RA participating in a tapering trial.

Methods: Patients, participating in the 1-year open-label pragmatic randomised controlled TapERA (Tapering Etanercept in RA) trial, were included in the analysis. Patients had to be in DAS28CRP or ESR remission ( $\geq 6$ months) and treated with etanercept $50 \mathrm{mg}$ weekly ( $\geq 1$ year). Participants were randomised to continue etanercept $50 \mathrm{mg}$ weekly or to taper to $50 \mathrm{mg}$ every other week.

The FLARE-RA questionnaire was completed every 3 months in the trial. This questionnaire consists of 13 questions on a Likert-scale from 1 to 6 reflecting 'completely untrue' to 'completely true.' Validation by Fautrel et al. leaded to elimination of 2 questions ('steroid intake' and 'overall worsening of RA') and rescaling to $0-10$. Our outcomes were based on these 3 versions of the questionnaire, namely 13 questions (13q), 11 questions (11q) and rescaled 11 questions (r11q). The FLARE-RA questionnaire can be divided in 2 subscales: the FLARE-RA arthritis subscale (questions regarding morning stiffness, night disturbances, joint swelling, joint pain, analgesics) and FLARE-RA general symptoms subscale (questions regarding fatigue, functional limitation, irritability, mood disturbances, withdrawal, need for help).

The total FLARE-RA score was calculated by taking the average of all the questions per time point. A flare was defined according to the OMERACT definition, namely an increase in DAS28CRP $>1.2$ compared to baseline or increase in DAS$28 \mathrm{CRP}>0.6$ and current DAS28CRP $\geq 3$.2. All the total FLARE-RA scores of the baseline, month 3,6 and 9 visit were grouped and the mean \pm standard deviation (SD) FLARE-RA score was compared between patients with or without an OMERACT flare on the next study visit using the Mann-Whitney $U$ test. Logistic regressions using the total FLARE-RA score to predict an OMERACT flare 3 months later were carried out for the 13q, 11q and r11q versions and the FLARE-RA subscales. Missing data were imputed using expectation maximisation.

Results: Sixty-six patients (68\% female, mean \pm SD age of $55 \pm 11$ years) completed the FLARE-RA questionnaire. This yielded 264 FLARE-RA scores, of which the total mean \pm SD FLARE-RA score was $2.1 \pm 1.0$ and $2.7 \pm 1.1$ for patients without and with an OMERACT flare on the next study visit, respectively $(p<0.01)$. This was comparable for the $11 q$ and $r 11 q$ versions (Table 1$)$. For the total FLARE-RA score (13q), the odds ratio of having an OMERACT flare 3 months later is $1.6(95 \%$ confidence interval $(\mathrm{Cl}) 1.2-2.2, \mathrm{p}=0.004)$. This was $1.5(95 \% \mathrm{Cl} 1.1-2.1, \mathrm{p}=0.006)$ for the $11 \mathrm{q}$ and $1.2(95 \% \mathrm{Cl} 1.1-1.4, \mathrm{p}=0.006)$ for the r11q version. The odds ratio of having an OMERACT flare on the next visit was $1.5(95 \% \mathrm{Cl} 1.2-2.0, \mathrm{p}=0.002)$ and $1.4(95 \% \mathrm{Cl} 1.0-2.0, \mathrm{p}=0.025)$ for the arthritis and general symptoms subscale, respectively.

Table 1. Comparison of overall total FLARE-RA scores between patients with or without an OMERACT flare on the next visit

\begin{tabular}{lcccc}
\hline & $\begin{array}{c}\text { Questionnaire } \\
\text { version }\end{array}$ & $\begin{array}{c}\text { No OMERACT flare } \\
\text { on next visit }\end{array}$ & $\begin{array}{c}\text { OMERACT flare } \\
\text { on next visit }\end{array}$ & P-value \\
\hline Overall total & $13 \mathrm{q}$ & $2.1 \pm 1.0$ & $2.7 \pm 1.1$ & 0.002 \\
$\quad$ FLARE-RA score & $11 \mathrm{q}$ & $2.2 \pm 1.1$ & $2.7 \pm 1.1$ & 0.004 \\
(mean \pm SD) & r11q & $2.3 \pm 2.1$ & $3.4 \pm 2.2$ & 0.004 \\
\hline
\end{tabular}

Overall total FLARE-RA score was derived by grouping the total FLARE-RA scores of the baseline, month 3,6 and 9 visit.

Conclusion: Higher total FLARE-RA questionnaire scores seem to indicate a higher risk of an OMERACT flare 3 months later, regardless of which versions or subscales of the FLARE-RA questionnaire were used. Hence, our findings suggest that the FLARE-RA questionnaire could be used as a predictive tool for flares.

Disclosure of Interests: Delphine Bertrand: None declared, Diederik De Cock: None declared, Veerle Stouten: None declared, Sofia Pazmino: None declared, Anneleen Moeyersoons: None declared, Johan Joly: None declared, Rene Westhovens Grant/research support from: Celltrion Inc, Galapagos, Gilead, Consultant of: Celltrion Inc, Galapagos, Gilead, Speakers bureau: Celltrion Inc, Galapagos, Gilead, Patrick Verschueren Grant/research support from: Pfizer unrestricted chair of early RA research, Speakers bureau: various companies

DOI: 10.1136/annrheumdis-2020-eular.3644

\section{SAT0029 PATIENT-PHYSICIAN DISCORDANCE IN ASSESSMENT OF DISEASE ACTIVITY IN RHEUMATOID ARTHRITIS}

L. Brites $^{1}$, F. Costa ${ }^{1}$, J. Dinis de Freitas ${ }^{1}$, M. Luis ${ }^{1}$, A. R. Prata ${ }^{1}$, H. Assunção ${ }^{1}$, L. Saraiva ${ }^{1}$, M. Sousa ${ }^{1}$, A. R. Cunha ${ }^{2}$, J. A. P. Da Silva ${ }^{1,3}$, C. Duarte ${ }^{1,3} .^{1}$ Centro Hospitalar e Universitário de Coimbra, Rheumatology, Coimbra, Portugal; ${ }^{2}$ Centro Hospitalar Baixo Vouga, Aveiro, Portugal; ${ }^{3}$ Coimbra Institute for Clinical and Biomedical Research(i.CIBR), Faculty of Medicine, Coimbra, Portugal

Background: In rheumatoid arthritis (RA), global disease activity is commonly assessed, from the patient's and the physician's perspective, through a 100mm VAS. Previous studies have commonly shown a considerable discrepancy between the patient's and physician's assessment.

Objectives: This study aimed evaluating patient-physician discordance in the assessment of disease activity and to explore its determinants.

Methods: Cross sectional study including RA patients (ACR/EULAR 2010 classification criteria), aged $\geq 18$ years, followed in a single tertiary centre. Data were collected from the most recent evaluation including sociodemographic features, disease duration (years), disease activity (DAS 28 3V-PCR), tender and swollen joint count 0-28 (TJC and SJC), VAS-pain-patient, patient and physician global assessment (PGA and PhGA respectively), erythrocyte sedimentation rate (ESR), C-reactive protein (CPR), Health assessment questionnaire (HAQ) and EuroQo five-dimension scale (EQ5D). The discrepancy between patients and physicians ( $\triangle P P h G A)$ was defined as PGA minus PhGA, and a difference $>120 \mathrm{mml}$ was considered as "discordant". A descriptive analysis was performed and variables described as proportions or means (+/- SD), as adequate. Correlation between $\triangle \mathrm{PPhGA}$ and other variables was assessed through Pearson's correlation and comparison between groups through t-test. Variables with $p<0.05$ or otherwise considered clinically relevant were included in multiple linear regression analysis to identify predictors for $\triangle \mathrm{PPhGA}$. A $\mathrm{p} \leq 0.05$ was considered statistically significant. Results: In total, 467 patients with RA were included $(81.2 \%$ female; mean age $63.9 \% \pm 12.2$ years). PGA and PhGA were discordant in $61.7 \%$ of the cases, the patient scoring higher than the physician in $95 \%$ of these cases. The proportion of concordance increased $(p<0.01)$ when considering only patients in remission (DAS 28 3V <2.6), (Graph 1). $\triangle \mathrm{PPhGA}$ was moderately correlated with VASpain-patient $(r=0.59)$ and weakly correlated with SJC $(r=-0.12), \mathrm{HAQ}(r=0.27)$, EQ5D $(r=-0.28)$ and age $(r=0.21)$; all $p<0.01$. In multivariate analysis, VAS-painpatient $(\beta 0.74,95 \% \mathrm{Cl} 0.62-0.88, p=0.00)$ and TJC $(\beta 0.16,95 \% \mathrm{Cl} 0.45-0.48$ $\mathrm{p}=0.02)$ remained associated with a higher $\triangle \mathrm{PPhGA}$.

Conclusion: Our study confirmed that a significant discrepancy between patients and physicians in the assessment of global disease activity is frequent in clinical practice probably due to valorization of different parameters. This was much less pronounced among patients in remission. Higher VAS-pain-patient and TJC were independent predictors of greater discrepancy between patients and physician's assessment.

\section{Graph 1. Concordance level(\%) between PGA and PhGA according to the disease activity}

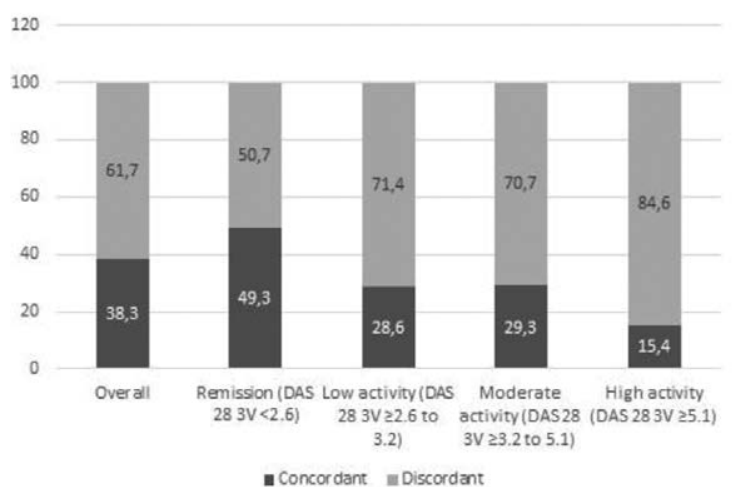

Disclosure of Interests: Luisa Brites: None declared, Flavio Costa: None declared, João Dinis de Freitas: None declared, Mariana Luis: None declared, Ana Rita Prata: None declared, Helena Assunção: None declared, LILIANA SARAIVA: None declared, Marlene Sousa: None declared, Ana Rita Cunha: None declared, José Antonio P. da Silva Grant/research support from: Pfizer, Abbvie, Consultant of: Pfizer, AbbVie, Roche, Lilly, Novartis, Catia Duarte: None declared DOI: 10.1136/annrheumdis-2020-eular.1536

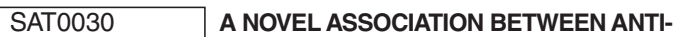 CARBAMYLATED ANTIBODIES AND INTERSTITIAL LUNG DISEASE IN PATIENTS WITH RHEUMATOID ARTHRITIS}

R. Castellanos-Moreira ${ }^{1}$, S. Rodriguez-Garcia ${ }^{1}$, K. Cajiao $^{1}$, G. Jimenez ${ }^{1}$, M. J. Gomara ${ }^{2}$, V. Ruiz ${ }^{1}$, I. Casafont-Solé ${ }^{3}$, J. Ramirez ${ }^{1}$, J. Gomez Puerta ${ }^{1}$ S. Holgado Pérez ${ }^{3}$, J. D. D. Cañete ${ }^{1}$, I. Haro ${ }^{2}$, R. Sanmartí ${ }^{1}{ }^{1}$ Hospital Clínic de 
Barcelona, Rheumatology, Barcelona, Spain; ${ }^{2}$ IQAC-CSIC, Barcelona, Spain; ${ }^{3}$ Hospital Germans Trias i Pujol, Rheumatology, Badalona, Spain

Background: Interstitial lung disease (ILD) is associated with a significant increase in morbidity and mortality in patients with rheumatoid arthritis (RA). Therefore, an early diagnosis is fundamental. Anti-carbamylated proteins (AntiCarP) have been described in different chronic respiratory diseases without a previous history of RA.

Objectives: The aim of this study was to analyse the association between AntiCarP and ILD in RA patients.

Methods: We performed a cross-sectional study, including RA patients fulfilling the 2010 ACR/EULAR criteria. The main population comprised 2 groups: 1) RA patients diagnosed with ILD (RA-ILD group) and 2) RA patients without ILD (non-ILD RA group). ILD was diagnosed by high-resolution tomography and confirmed by a multidisciplinary committee. Three IgG Anti-CarP autoantibodies against fetal calf serum (Anti-FCS), fibrinogen (Anti-Fib), and fibrine/filagrine homocitrullinated peptide (Anti-CFFHP) and one IgA against FCS (Anti-FCS-IgA) were determined by home-made ELISA. Associations between Anti-CarPs and ILD were explored using multivariable logistic regression adjusted by a set of variables known to be related to the development of ILD: smoking, sex, age, RA disease duration, RF and ACPA. An independent replication sample was obtained to validate our findings from another hospital.

Results: The main population included 179 patients: 37 were included in the RA-ILD group, and 142 in the non-ILD RA group. Most patients were female (79\%), with a mean age of $59.7 \pm 13$ years with a mean disease duration of $6.6 \pm 5$ years. Baseline features are shown in table 1 . The replication sample was composed of 25 patients in the RA-ILD group and 50 patients in the non-ILD RA group. We found that Anti-CarPs specificities were more frequent in RA-ILD patients (Anti-FCS $70 \%$ vs. $43 \%$; Anti-Fib $73 \%$ vs. $51 \%$; Anti-CFFHP $38 \%$ vs. $19 \%$; Anti-CarP-IgA $51 \%$ vs. $20 \%$, p $<0.05$ for all comparisons). Serum mean titers of Anti-CarPs were higher in RA-ILD patients with significant statistical differences for all of them, except Anti-Fib. The multivariate analysis showed that Anti-CarPs specificities were independently associated with ILD (Anti-FCS (OR: 3.42; CI95\%: 1.13-10.40), Anti-Fib (OR: 2.85; Cl95\%: 0.83-9.70), Anti-CFFHP (OR: 3.11 ; Cl95\%: 1.06-9.14) and Anti-FCS-IgA (OR: $4.30 ;$ CI95\%: 1.41-13.04). In the replication sample our findings were validated only for Anti-FCS (OR: 10.42; CI95\%: 1.68-64.46).

TABLE 1. Main population demographic, clinical, therapeutic, and autoantibody status features.

\begin{tabular}{|c|c|c|c|}
\hline & $\begin{array}{c}\text { RA-ILD } \\
n: 37\end{array}$ & $\begin{array}{c}\text { Non-ILD RA } \\
n: 142\end{array}$ & $p$ value \\
\hline Female (\%) & $25(68)$ & $116(82)$ & NS \\
\hline Age mean $( \pm S D)$ & $67.3(10.1)$ & $57.7(12.9)$ & $<0.005$ \\
\hline Mean disease duration $( \pm S D)$ & $11.6(7.1)$ & $5.3(13.3)$ & $<0.005$ \\
\hline Ever smokers (\%) & $21(57)$ & $62(44)$ & NS \\
\hline Smoking cumulative dose $( \pm S D)$ & $30.7(11.1)$ & $21.8(12)$ & $<0.005$ \\
\hline Caucasian (\%) & $31(84)$ & $120(85)$ & NS \\
\hline \multicolumn{4}{|l|}{ Treatment } \\
\hline Glucocorticoids (\%) & $25(68)$ & $81(57)$ & NS \\
\hline csDMARDs (\%) & $33(89)$ & $132(86)$ & NS \\
\hline MTX (\%) & $20(54)$ & $95(67)$ & NS \\
\hline bDMARDs (\%) & $11(30)$ & $36(25)$ & NS \\
\hline Mean DAS28 $( \pm S D)$ & $3.71(1.35)$ & $2.74(1.05)$ & $<0.005$ \\
\hline Erosive disease (\%) & $26(70)$ & $63(44)$ & $<0.005$ \\
\hline Mean HAQ-DI (Cl-95\%) & $0.69(0.53-0.85)$ & $0.31(0.24-0.38)$ & $<0.005$ \\
\hline ACPA positive (\%) & $29(78)$ & $99(70)$ & NS \\
\hline Median titer ACPA (IQR) CU & $674(2,215)$ & $143(1,132)$ & NS \\
\hline RF positive (\%) & $28(76)$ & $83(59)$ & NS \\
\hline Median titer RF (IQR) IU & $105(298)$ & $34(110)$ & NS \\
\hline
\end{tabular}

Conclusion: A strong association between RA-ILD and Anti-CarP was found independently of cofounders, including RF and ACPA. Our findings suggest a possible link between Anti-CarP and the development of ILD.

Disclosure of Interests: Raul Castellanos-Moreira Speakers bureau: Lilly, MSD, Sanofi, UCB, Sebastian Rodriguez-Garcia: None declared, Katherine Cajiao: None declared, Gabriela Jimenez: None declared, Maria Jose Gomara: None declared, Virginia Ruiz Speakers bureau: Lilly, Pfizer, Ivette Casafont-Solé: None declared, Julio Ramirez: None declared, José Gomez Puerta Speakers bureau: Abbvie, Eli Lilly, BMS, Roche and Pfizer, Susana Holgado Pérez: None declared, Juan de Dios Cañete: None declared, Isabel Haro: None declared, Raimón Sanmartí Speakers bureau: Abbvie, Eli Lilly, BMS, Roche and Pfizer

DOI: 10.1136/annrheumdis-2020-eular.1993

\section{SAT0031 CORRELATION BETWEEN IRREVERSIBLE PHYSICAL DISABILITY AND JOINT DAMAGE IN RHEUMATOID ARTHRITIS}

E. Cipolletta ${ }^{1}$, A. Incorvaia ${ }^{1}$, R. Mashadi Mirza ${ }^{2}$, A. DI Matteo ${ }^{1,3}$, M. Tardella ${ }^{1}$, W. Grassi' ${ }^{1}$, E. Filippucci'. ${ }^{1}$ Polytechnic University of Marche, Rheumatology Unit - Department of Clinical and Molecular Sciences, Ancona, Italy; ${ }^{2}$ ASL Umbria 1, Department of Radiology - Città Di Castello Hospital, Città Di Castello, Italy; ${ }^{3}$ University of Leeds, Leeds Institute of Rheumatic and Musculoskeletal Medicine, Leeds, United Kingdom

Background: In rheumatoid arthritis (RA), irreversible physical disability appears to be more clearly associated with cartilage damage rather than with bone erosions $(\mathrm{BE})$ using conventional radiography $(\mathrm{CR})$ imaging.

Objectives: To investigate the correlation between the ultrasound (US) and CR findings indicative of joint damage and irreversible physical disability in patients with RA in sustained clinical remission.

Methods: Patients in sustained clinical remission according to the Simplified Disease Activity Index (SDAl) $\leq 3.3$ for at least 6 months were enrolled. The following data were regireted: age, disease duration, anti-cyclic citrullinated peptide (ACPA) antibody and rheumatoid factor (RF) status, Health Assessment Questionnaire (HAQ), CR of hands and feet [evaluated using the Simple Erosion Narrowing Score (SENS) method]. A standardized US examination was carried out to investigate the presence of BE (lateral side of II metacarpophalangeal, $\mathrm{V}$ metacarpophalangeal and $\mathrm{V}$ metatarsophalangeal joints and ulnar styloid) and of cartilage damage (II to $\mathrm{V}$ metacarpal heads), bilaterally. $\mathrm{BE}$ and cartilage damage were assessed according to OMERACT definitions. A semiquantitative scoring system for both BE (1) and cartilage damage (2) was adopted.

Results: Ninety patients were consecutively enrolled. Average time for US evaluation was $10 \pm 2$ minutes. Both SENS-JSN and US score of cartilage damage (US-CD) were significantly associated with irreversible disability $(R=0.39$, $p<0.01$ and $R=0.46, p<0.01)$. US and $C R$ showed a moderate agreement in the evaluation of cartilage damage (kappa $=0.52,95 \%$ confidence interval: 0.44-0.61).

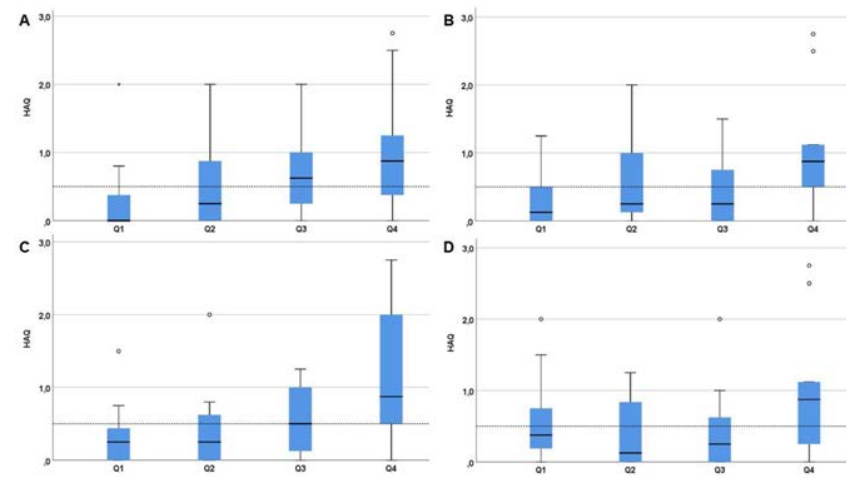

Figure 1. shows the association between disability and structural damage (A: US-CD B: US-BE, C: SENS-JSN and D: SENS-BE).After adjusting for confounding factors (age, disease duration, ACPA and RF status, SENS-BE and US-BE) cartilage damage was the only significant predictor of irreversible disability both using $C R\left(R^{2}=0.31\right.$, adjusted $R^{2}=0.26$, standardized $\beta=0.36, p<0.01)$ and $U S\left(R^{2}=0.31\right.$, adjusted $R^{2}=0.26$, standardized $\beta=0.34$, $\mathrm{p}<0.01)$.

Conclusion: This study supports the hypothesis that cartilage damage is more relevant than $\mathrm{BE}$ in determining irreversible disability in RA. Our data provide further evidence in favor of the external validity of US in the assessment of cartilage damage.

\section{References:}

[1] Ohrndorf S, Messerschmidt J, Reiche BE, et al. Evaluation of a new erosion score by musculoskeletal ultrasound in patients with rheumatoid arthritis: is US ready for a new erosion score? Clin Rheumatol. 2014;33:1255-62.

[2] Mandl P, Studenic P, Filippucci E, et al. Development of semiquantitative ultrasound scoring system to assess cartilage in rheumatoid arthritis. Rheumatology (Oxford). 2019;58:1802-11.

Disclosure of Interests: Edoardo Cipolletta: None declared, Antonella Incorvaia: None declared, Riccardo Mashadi Mirza: None declared, Andrea Di Matteo Grant/research support from: the publication was conducted while Dr. Di Matteo was an ARTICULUM fellow, Marika Tardella: None declared, Walter Grassi 